\author{
D. A. McClain - D. Abraham $\cdot$ J. Rogers $\cdot$ R. Brady $\cdot$ \\ P. Gault • R. Ajioka $\cdot$ J. P. Kushner
}

\title{
High prevalence of abnormal glucose homeostasis secondary to decreased insulin secretion in individuals with hereditary haemochromatosis
}

Received: 2 December 2005 / Accepted: 14 January 2006 / Published online: 15 March 2006

C) Springer-Verlag 2006

\begin{abstract}
Aims/hypothesis: The prevalence and mechanisms of diabetes in hereditary haemochromatosis are not known. We therefore measured glucose tolerance, insulin secretory capacity and insulin sensitivity in adults with haemochromatosis. Subjects and methods: Subjects recruited from referrals to a haemochromatosis clinic underwent OGTT and frequently sampled IVGTT. A chart review of former clinic patients was also performed. Results: The prevalence of diabetes (23\%) and IGT (30\%) was increased in haemochromatosis compared with matched control subjects ( $0 \%$ diabetes and $14 \%$ IGT). Subjects with haemochromatosis and diabetes were overweight $(14 \%)$ or obese $(86 \%)$. The prevalence of diabetes, as determined by chart review of fasting glucose values, in subjects who had haemochromatosis and were in the 4079 years age range was $26 \%$. Overall, patients with haemochromatosis and control subjects had similar values for acute insulin response to glucose and insulin sensitivity. However, patients with haemochromatosis and IGT had a $68 \%$ decrease in acute insulin response to glucose $(p<0.02)$ compared with those with NGT. They were not insulin-resistant, exhibiting instead a $62 \%$ increase in insulin sensitivity (NS). Haemochromatosis subjects with diabetes exhibited further declines in acute insulin response to glucose, insulin resistance, or both.
\end{abstract}

D. A. McClain · D. Abraham · J. Rogers · R. Brady .

P. Gault · R. Ajioka · J. P. Kushner

Department of Internal Medicine,

University of Utah School of Medicine,

Salt Lake City, UT, USA

D. A. McClain

Salt Lake City Veterans Administration Health Care System,

Salt Lake City, UT, USA

D. A. McClain $(\bowtie)$

Division of Endocrinology, Metabolism and Diabetes,

University of Utah School of Medicine,

30 N. 2030 East,

Salt Lake City, UT 84132, USA

e-mail: donald.mcclain@hsc.utah.edu

Tel.: +1-801-585-0954

Fax: +1-801-585-0956
Conclusions/interpretation: Diabetes and IGT are common in haemochromatosis, justifying screening for diabetes and therapeutic phlebotomy. The major abnormality associated with IGT is decreased insulin secretory capacity. Diabetes is usually associated with obesity and concomitant insulin resistance.

Keywords Diabetes · Haemochromatosis - Impaired glucose tolerance Insulin resistance Insulin secretion

Abbreviations AIRg: acute insulin response to glucose * DI: disposition index - FSIVGTT: frequently sampled intravenous glucose tolerance test - Si: insulin sensitivity . QUICKI: Quantitative Insulin-sensitivity Check Index

\section{Introduction}

Hereditary haemochromatosis is transmitted as an autosomal recessive trait and occurs in approximately five per 1,000 white people of northern European descent $[1,2]$. Most patients with haemochromatosis are homozygous for a single nucleotide substitution $(\mathrm{C} 282 \mathrm{Y})$ in the haemochromatosis gene (HFE) [3]. The wild-type HFE protein forms a heterodimer with $\beta_{2}$-microglobulin. The $\mathrm{C} 282 \mathrm{Y}$ mutation of $H F E$ prevents binding of $\beta_{2}$-microglobulin, resulting in unstable production of HFE protein on the cell surface [4]. It has not been established how this interaction is related to the observed changes in iron balance. Normal $H F E$ expression is required for regulation of hepcidin, a small hepatic peptide whose production is induced by increased hepatic iron and inflammation [5]. Failure to induce hepcidin in haemochromatosis results in unregulated iron entry into the circulation from the gastrointestinal tract and macrophages [6].

Hereditary haemochromatosis was originally described as 'bronze diabetes' and defined by the triad of cirrhosis, skin pigmentation and diabetes. Since identification of the $H F E$ gene, however, it has become clear that phenotypic expression of the homozygous genotype may vary from a fully penetrant clinical syndrome to a simple laboratory 
abnormality, an elevated transferrin saturation without iron overload or organ injury $[1,7]$. There is controversy about the frequency of morbidity that accompanies haemochromatosis. In relatively small clinical studies, the prevalence of diabetes in haemochromatosis has been found to be in the range $7-40 \%[8,9]$. Many of these studies are affected by selection bias, with diabetes being assessed in subjects who have sought medical help because of associated morbidity. The pathophysiology of the diabetes associated with haemochromatosis and iron overload is poorly understood, with evidence suggesting that both insulin deficiency and insulin resistance are contributing factors [10-12]. Some of these studies are difficult to interpret, because subjects with established diabetes were studied, in which case the attendant hyperglycaemia may itself have resulted in insulin resistance and insulin secretory abnormalities [13]. Furthermore, the studies most clearly demonstrating iron effects on insulin sensitivity $(\mathrm{Si})$ in patients without diabetes are those of subjects with transfusional or idiopathic iron overload, and not of subjects with haemochromatosis $[11,14]$.

We have recently described mouse models of haemochromatosis, namely mice with targeted deletion of Hfe or replacement of deleted wild-type $H f e$ with the cognate human mutation $\mathrm{C} 282 \mathrm{Y}$ [15]. These mice exhibited decreased insulin secretory capacity secondary to oxidative stress, decreased glucose-stimulated insulin secretion, and beta cell apoptosis. The mice had increased $\mathrm{Si}$ and did not develop diabetes. We therefore sought to determine the prevalence of diabetes in humans with haemochromatosis and whether the mechanism of diabetes primarily involved insulin secretory defects. We also performed a chart review of subjects with haemochromatosis who were referred before our diabetes-screening programme was initiated. We report a significant prevalence of diabetes and IGT in individuals with haemochromatosis related to decreased insulin secretory capacity.

\section{Subjects and methods}

\section{Subjects}

The study participants were recruited from all consecutive referrals to the Haemochromatosis Research Clinic at the University of Utah School of Medicine from 2000 to the present. All of these referred patients agreed to serve in the study and informed consent was obtained from those who agreed, although one was excluded because of serious associated illness (heart failure, cirrhosis, diabetes and panhypopituitarism). Siblings and other relatives of the referred subjects were screened for haemochromatosis mutations and those relatives who were found to be homozygous wild-type or heterozygous wild-type/mutant at the HFE locus served as controls. (heterozygotes for $H F E$ mutations are not iron-overloaded and do not suffer associated morbidities [16]). The characteristics of the study population are shown in Table 1. Heterozygote controls did not differ from wild-types in serum ferritin,
BMI, age or sex. The subjects were all white, one being of white Hispanic descent. The study was approved by the University of Utah Institutional Review Board and the Advisory Committee to the General Clinical Research Center (GCRC).

\section{Genotyping}

$H F E$ genotyping was performed using allele-specific PCR primers [17]. The amplification protocol was modified for use with an air thermalcycler (Idaho Technologies, Salt Lake City, UT, USA). The C282Y-specific reaction was carried out in a $2 \mathrm{mmol} / \mathrm{l} \mathrm{Mg}$ solution and all other reactions were carried out in $3 \mathrm{mmol} / \mathrm{l} \mathrm{Mg}$. Temperatures for the reactions were: denaturation $94^{\circ} \mathrm{C}$; annealing $56^{\circ} \mathrm{C}$; and elongation $72^{\circ} \mathrm{C}$. Denaturation and annealing times were $0 \mathrm{~s}$ and elongation time was $15 \mathrm{~s}$. A pre-denaturation step of $94^{\circ} \mathrm{C}$ for $15 \mathrm{~s}$ was used for each reaction.

\section{Clinical studies}

After a $12 \mathrm{~h}$ overnight fast, an i.v. catheter was sited and subjects underwent an OGTT using a $75 \mathrm{~g}$ oral glucose load. Glucose and insulin values were determined at 0,30 , 60, 90 and $120 \mathrm{~min}$. Glucose tolerance status was defined according to World Health Organization criteria [18]: IFG represents fasting glucose values of $110-125 \mathrm{mg} / \mathrm{dl}(6.06$ $6.99 \mathrm{mmol} / \mathrm{l})$; and IGT by $2 \mathrm{~h}$ post-challenge levels of 140 $199 \mathrm{mg} / \mathrm{dl}(7.72-11.02 \mathrm{mmol} / \mathrm{l})$. Insulin was assayed by RIA using a kit that has $20 \%$ cross-reactivity with proinsulin (Diagnostic Products, Los Angeles, CA, USA). The next morning, also after a $12 \mathrm{~h}$ fast, the subjects underwent an IVGTT [19]. The subjects were given a $300 \mathrm{mg} / \mathrm{kg}$ glucose load over $1 \mathrm{~min}$, with blood samples for insulin and glucose determination collected at 1 min intervals for $6 \mathrm{~min}$, then at 2 min intervals until $18 \mathrm{~min}$. At $20 \mathrm{~min}$, regular insulin $(0.03 \mathrm{U} / \mathrm{kg})$ was infused over a 1 min interval. Blood was then drawn at 1 min intervals for $4 \mathrm{~min}$, then every $10 \mathrm{~min}$ until a total of $180 \mathrm{~min}$ had elapsed. Results were analysed by MINMOD software [20] to determine the acute insulin response to

Table 1 Characteristics of the study population

\begin{tabular}{llc}
\hline & Control & Haemochromatosis \\
\hline$n$ & 14 & 30 \\
Age (years) & $49.7 \pm 3.0$ & $50.1 \pm 2.8$ \\
BMI $\left(\mathrm{kg} / \mathrm{m}^{2}\right)$ & $26.2 \pm 0.8$ & $26.7 \pm 1.0$ \\
Serum ferritin $(\mathrm{ng} / \mathrm{ml})$ & $320 \pm 140$ & $1501 \pm 287 * * *$ \\
Genotype $^{\dagger}$ & $29 \% \mathrm{wt} / \mathrm{wt} ; 64 \% \mathrm{Y} / \mathrm{wt}$ & $87 \% \mathrm{Y} / \mathrm{Y} ;$ \\
& $7 \% \mathrm{D} / \mathrm{wt}$ & $13 \% \mathrm{Y} / \mathrm{D}$ \\
Sex & $29 \% \mathrm{female}$ & $26 \%$ female \\
& $71 \%$ male & $74 \%$ male \\
\hline
\end{tabular}

$* * * p<0.001$ compared with controls

${ }^{\dagger} w t$ Wild-type, Y C282Y, D H63D 
glucose (AIRg; a measure of insulin secretory capacity) and Si. Most of the study subjects also underwent percutaneous liver biopsy for iron and histological analysis.

Chart reviews were performed on all existing charts from the 505 haemochromatosis homozygotes as ascertained in the Hematology Research Clinic of the Huntsman GCRC at the University of Utah from 1975 to the initiation of this study in 2000 . Eighty-three subjects were $<40$ years old at the time of study and were not considered because of the known age-dependence of diabetes. Of the remaining 422 subjects, fasting glucose values were available on 137 (32\%) subjects; fasting was assured because the blood samples had been drawn while the subjects were inpatients in the GCRC. Of the remaining 285 potential subjects, 135 $(47 \%)$ had definite statements by self-report of either diabetes or lack of diabetes in their charts. The remaining 150 charts $(36 \%)$ contained inadequate information (e.g. glucose levels that could not be verified as fasting). Overall, $64 \%$ of the charts of potential subjects $>40$ years of age were used in the review.

\section{Statistics}

Statistical analyses were performed using SPSS software (SPSS, Chicago, IL, USA). Comparisons of the prevalence of diabetes and IGT in haemochromatosis and control subjects were by $\chi^{2}$ analysis. AIRg and Si were compared using non-parametric methods (Mann-Whitney).

\section{Results}

Prevalence of diabetes, IGT and IFG

The results of OGTTs are shown in Fig. 1. Of the 14 control subjects, two $(14 \%, 95 \%$ CI 3-41) had abnormal glucose homeostasis. Of the 30 subjects with haemochromatosis, 16 (53\%, 95\% CI 36-70) had abnormal glucose homeostasis $\left(p<0.02\right.$ compared with controls by $\chi^{2}$ test). In control subjects, the cases of abnormal glucose homeostasis included none $(0 \%)$ with diabetes, one $(7 \%)$ with IGT only and one (7\%) with both IFG and IGT. Of the patients with haemochromatosis, seven $(23 \%, 95 \%$ CI 12-41) had diabetes ( $p<0.05$ compared with controls). One $(3 \%)$ had IFG only, four $(13 \%)$ had IGT only, and four $(13 \%)$ had both IFG and IGT. There were no significant differences between the subgroups of differing glucose tolerance status in age, ferritin or genotype, although there was a non-significant trend toward higher serum ferritin in the groups with IGT compared with those with NGT (Table 2). The diabetic group had a significantly higher average BMI than the other groups (Table 2, $p<0.01$ compared with both other groups). All cases of diabetes occurred in overweight subjects whose BMI values were $>25 \mathrm{~kg} / \mathrm{m}^{2}$, and six of those seven had BMI values $>30 \mathrm{~kg} / \mathrm{m}^{2}$. All cases of diabetes occurred in men $(p=0.13)$.

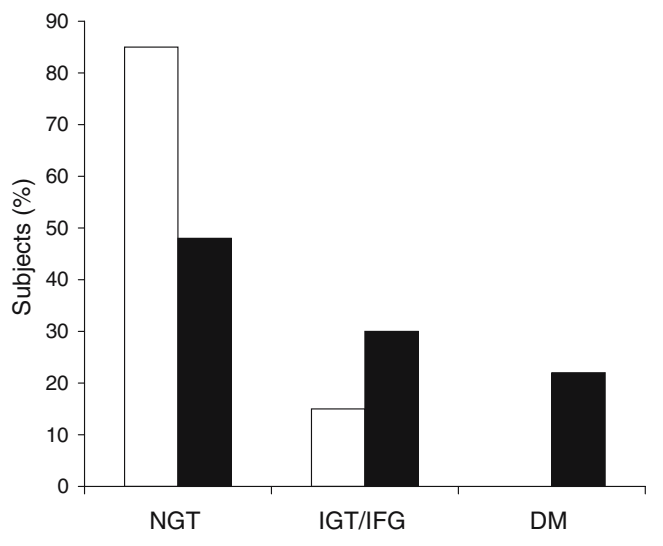

Fig. 1 Frequency of NGT, IGT and diabetes (DM) in controls (open bars) and subjects with haemochromatosis (black bars). The subjects described in Table 1 underwent OGTTs using a $75 \mathrm{~g}$ glucose load. Diabetes and IGT were defined according to World Health Organization criteria [18]

Historical review of diabetes prevalence data in haemochromatosis referrals to the Haemochromatosis Research Clinic at the University of Utah

The prevalence of diabetes in haemochromatosis can only be estimated from the small sample of recent clinic referrals reported here. To assess the prevalence of diabetes in a larger cohort, we reviewed clinical information available on homozygotes $>40$ years old, ascertained between 1975 and 1999. We determined the prevalence of diabetes as defined by fasting glucose criteria (Table 3) or, in charts where fasting glucose values were unavailable, by selfreport (see below).

Fasting blood glucose values were available in 104 male and 33 female probands seen between 1975 and 1998 (Table 3). The overall prevalence of abnormal fasting glucose values in this group were: IFG $13 \%(95 \%$ CI $8-20)$ ) diabetes $26 \%$ (95\% CI 20-34). Thirty-two of the males $(31 \%)$ and four of the females $(12 \%)$ had diabetes. The difference in the frequency of diabetes between the sexes is significant $\left(p<0.05\right.$ by $\chi^{2}$ test). All individuals with diabetes were heavily iron-loaded (median serum ferritin $2,000 \mathrm{ng} / \mathrm{ml}$ ). Of the male subjects with fasting glucose who also underwent liver biopsy, 23 of the diabetics (72\%) had biopsy-proven cirrhosis and five (16\%) had moderate

Table 2 Characteristics of the haemochromatosis subpopulations

\begin{tabular}{llcl}
\hline & NGT $(n=14)$ & IFG/IGT $(n=9)$ & $\begin{array}{l}\text { Diabetes } \\
\text { mellitus }(n=7)\end{array}$ \\
\hline Age (years) & $47.4 \pm 4.7$ & $51.7 \pm 5.4$ & $53.7 \pm 3.8$ \\
Serum ferritin & $992 \pm 187$ & $2063 \pm 716$ & $1814 \pm 659$ \\
$(\mathrm{ng} / \mathrm{ml})$ & & & \\
BMI $\left(\mathrm{kg} / \mathrm{m}^{2}\right)$ & $25.6 \pm 1.5$ & $23.8 \pm 1.2$ & $31.8 \pm 1.4 * *$ \\
Sex & $36 \%$ female & $33 \%$ female & $0 \%$ female \\
& $64 \%$ male & $67 \%$ male & $100 \%$ male \\
\hline
\end{tabular}

$* * p<0.01$ compared with either group or total 
Table 3 Prevalence of diabetes by fasting glucose values in historical review of haemochromatosis homozygotes

\begin{tabular}{lrlcl}
\hline Sex & $n$ & Diabetic (\%) & Diabetic with cirrhosis or fibrosis (\%) & Non-diabetic with cirrhosis or fibrosis (\%) \\
\hline Male & 104 & $31^{*}$ & $87(28 / 32)^{* * *}$ & $46(123 / 267)^{* * *}$ \\
Female & 33 & $12^{*}$ & $100(2 / 2)$ & $25(29 / 117)^{* * *}$ \\
Male+female & 137 & 26 & $88(30 / 34)^{* * *}$ & $40(152 / 384)^{* * *}$ \\
\hline
\end{tabular}

$* p<0.05$ for frequency of diabetes in males vs females

$* * * p<0.001$ for frequency of cirrhosis/fibrosis in diabetic vs non-diabetic

fibrosis. Only four (13\%) had normal liver architecture. Of the two female diabetic subjects who had liver biopsies, both had coexisting cirrhosis. Thus, $88 \%$ of the diabetics had cirrhosis or fibrosis, while only $40 \%$ of non-diabetics had cirrhosis or fibrosis $(p<0.0001)$. Of all subjects with cirrhosis or fibrosis, $39 \%$ had diabetes, whereas of all subjects without liver disease, only $10 \%$ had diabetes. It should be pointed out that these liver biopsies were not sought only in individuals with abnormal liver function tests or other clinical indications. Rather, they were performed for research and diagnostic purposes and were sought from the entire cohort of subjects. Thus, there should be little bias in terms of the prevalence of liver disease in the subgroups.

A chart review was also performed for clinic patients for whom there were no fasting glucose data, but in whom a history of diabetes or not was obtained by selfreport. The overall prevalence of diabetes in this group aged $50-79$ years was $22 \%$ in men and $17 \%$ in women, or $20 \%(95 \%$ CI $14-28 \%)$ in men plus women. This represents a significant increase in frequency $(p<0.0001)$ compared with normal controls, as reported in three studies of communities in Minnesota and Wisconsin with demographics similar to our largely northern European population [21].
A subgroup of the above were individuals who were not themselves referred because of haemochromatosis but who were found to have haemochromatosis in the course of family screening or screening at blood donation [22]. This clinically unselected group included 46 in the age range $50-79$ years, and six $(13 \%, 95 \%$ CI 6-26) had diabetes by self-report.

\section{Mechanism of glucose intolerance}

The data presented above reveal a significantly increased prevalence of abnormal glucose tolerance and diabetes in subjects with haemochromatosis. We next performed frequently sampled IVGTT (FSIVGTT) in order to determine whether the IGT was related to decreased insulin secretion or decreased insulin sensitivity. The total population of subjects with haemochromatosis had comparable insulin secretory capacity (AIRg, Fig. 2a) and Si (Fig. 2a) compared with controls. When haemochromatosis subjects were subdivided into those with NGT or abnormal glucose tolerance, those with NGT did not differ significantly from controls in either AIRg or $\mathrm{Si}$. The haemochromatosis subjects with IGT, however, had a $68 \%$ decrease in AIRg (Fig. 2a, $p<0.02$ by $t$ test) and a trend toward increased $\mathrm{Si}$
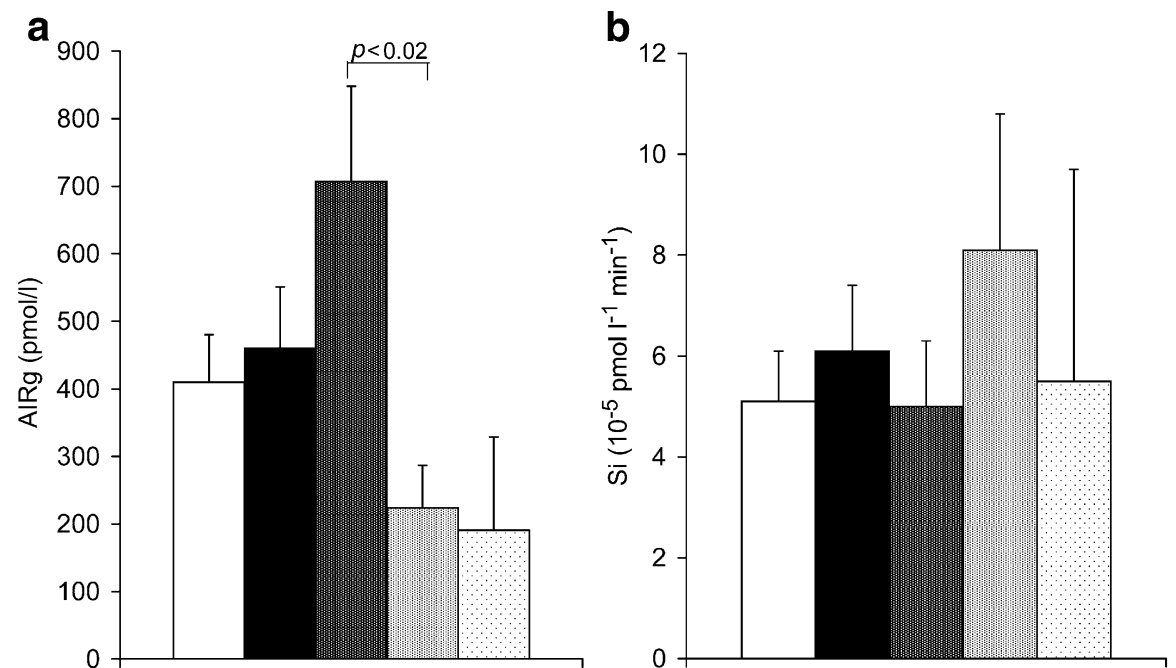

stippling) according to World Health Organization criteria [18]. The subjects described in Table 1 underwent FSIVGTT. Data were analysed by the Bergman minimal model using MINMOD software [20]. Subgroup sizes are given in Table 2

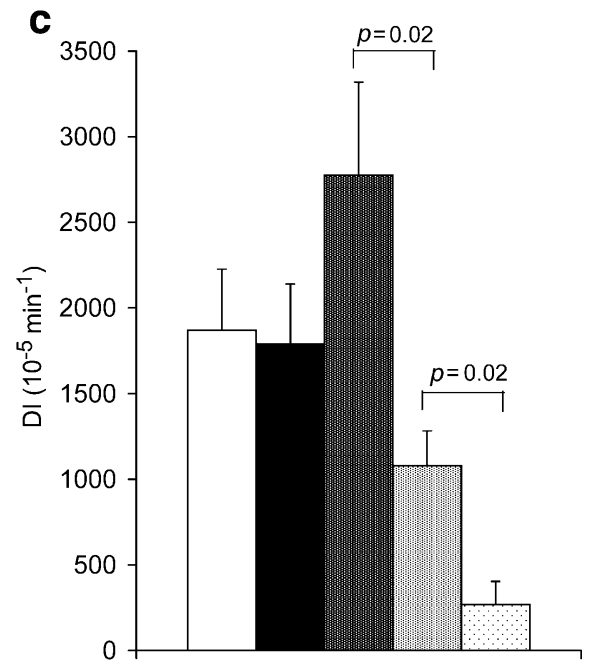

Fig. 2 Insulin secretion (AIRg) (a) Si (b) and glucose disposition haemochromatosis (all haemochromatosis subjects, black bars). Haemochromatosis subjects were further subdivided into those with NGT (dark stippling), IGT (medium stippling) and diabetes (light 
Fig. 3 Relationship between AIRg and $\mathrm{Si}$ in haemochromatosis subjects and controls. For reference, previously reported population means for normal adult males and females (solid line) and the 5th and 95th percentile ranges (dashed lines) from studies by Kahn et al. are also shown [23]. Mean data from normal controls (open box) and haemochromatosis subjects with either NGT (closed circle) or IGT (open triangle) are shown. Data from subjects with diabetes (open circles) are individually plotted to demonstrate their heterogeneity

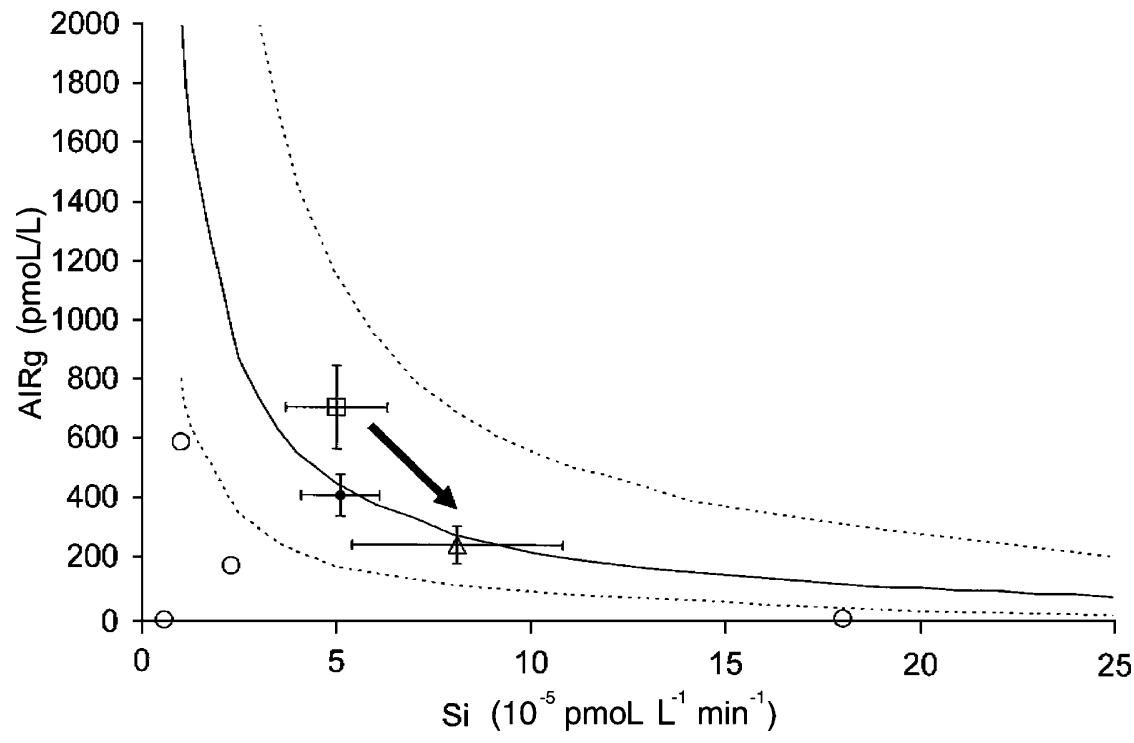

( $62 \%$ increase, Fig. $2 \mathrm{~b}, p=0.26)$ compared with controls. The subjects with haemochromatosis and abnormal glucose homeostasis had a $61 \%$ decrease in the product of the AIRg and $\mathrm{Si}$ (disposition index [DI], Fig. 2c, $p=0.02$ compared with those who had NGT), indicating that the changes in $\mathrm{Si}$ and $\mathrm{AIRg}$ did not follow the expected hyperbolic relationship [23] and were consistent with their decline in glucose tolerance. Haemochromatosis subjects with diabetes had lower AIRg and DI compared with those with NGT, but average $\mathrm{Si}$ was unchanged (Fig. 2a-c). There was no relationship between Si or AIRg and the presence or absence of cirrhosis (results not shown).

The above values of the AIRg were plotted as a function of Si (Fig. 3). Kahn has previously reported that these two variables follow a hyperbolic relationship in normal individuals; the solid and dashed lines indicate the mean, and 5th and 95th percentiles, for $\mathrm{AIRg}$ and $\mathrm{Si}$ in the healthy, non-diabetic population studied by Kahn [23]. Thus, for example, if insulin secretory capacity decreases but $\mathrm{Si}$ also increases within this normal relationship, NGT should be maintained; glucose intolerance develops when one variable or the other does not compensate and the individual departs from the normal hyperbolic relationship [23]. Control and haemochromatosis subjects with NGT have similar values for AIRg and Si (see Fig. 2). The haemochromatosis subjects with IGT have decreased AIRg and a trend toward increased Si. On average, however, these did not follow the expected hyperbolic relationship, as revealed by the downward shift in the group on this curve and the lowering of the DI (Fig. 2), presumably accounting for the IGT. The four individuals with diabetes who underwent FSIVGTT are plotted as individual values. Their insulin secretory capacities and Si differed widely, suggesting differing mechanisms underlying the transition from IGT to diabetes. One had markedly decreased insulin secretion $(\mathrm{AIRg}=5 \mathrm{pmol} / \mathrm{l})$ and enhanced insulin sensitivity $\left(\mathrm{Si}=18 \times 10^{-5} \mathrm{pmol} \cdot \mathrm{l}^{-1} \cdot \mathrm{min}^{-1}\right)$ despite obesity $(\mathrm{BMI}=30.5 \mathrm{~kg} /$ $\mathrm{m}^{2}$ ). A second was insulin resistant with near-normal insulin secretion $\left(\mathrm{AIRg}=587 \mathrm{pmol} / \mathrm{l}, \mathrm{Si}=1 \times 10^{-5} \mathrm{pmol} \cdot \mathrm{l}^{-1} \cdot \mathrm{min}^{-1}\right)$, and two others showed mixed defects.

The lack of insulin resistance in patients with haemochromatosis and IGT/IFG was further confirmed by analysis of Si by an independent test relying only on fasting data, the Quantitative Insulin-sensitivity Check
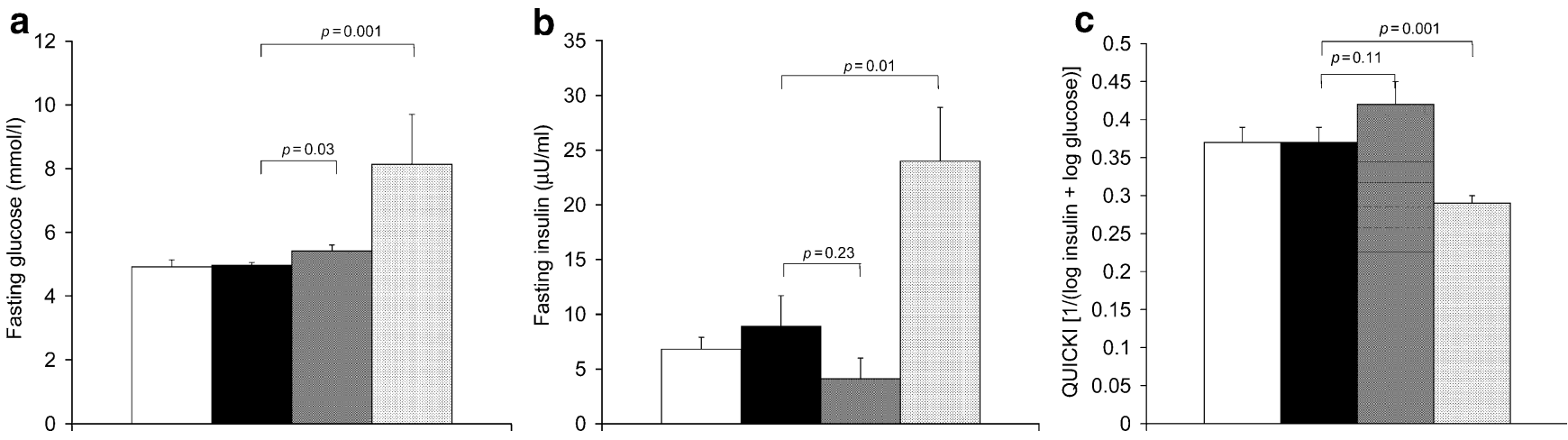

Fig. 4 Fasting glucose (a), insulin (b) and QUICKI (c) values for controls (open bars) and haemochromatosis subjects (all haemochromatosis, black bars; haemochromatosis with IGT/IFG, dark stippling; haemochromatosis with diabetes, light stippling) 
Index (QUICKI). The QUICKI index has been validated against the euglycaemic clamp, FSIVGTT and homeostasis model indices [24]. The control subjects with NGT did not differ from the haemochromatosis subjects with NGT in terms of fasting glucose, insulin or QUICKI (Fig. $4 \mathrm{a}-\mathrm{c}$ ). The haemochromatosis group with IGT/IFG, however, had a significantly higher fasting glucose despite a trend toward lower insulin values, and the QUICKI index was $14 \%$ higher $(p=0.11, \mathrm{NS}$ ). The haemochromatosis group with diabetes, on the other hand, had both significantly higher glucose and insulin levels, and a significant decrease in QUICKI. We also performed hyperinsulinaemic-euglycaemic glucose clamp studies (results not shown) that were consistent with the above data in showing no difference between controls $\left(9.2 \pm 1.4 \mathrm{mg} \cdot \mathrm{kg}^{-1} \cdot \mathrm{min}^{-1}\right)$ and haemochromatosis subjects with NGT $\left(8.6 \pm 1.1 \mathrm{mg} \cdot \mathrm{kg}^{-1} \cdot \mathrm{min}^{-1}\right)$, and a trend toward increased glucose disposal rate in the haemochromatosis subjects with IGT $\left(10.8 \pm 0.9 \mathrm{mg} \cdot \mathrm{kg}^{-1}\right.$. $\min ^{-1}, p=0.15$ compared with IGT).

\section{Discussion}

Diabetes is part of the classic triad used to define fully penetrant haemochromatosis. Prior to the discovery of the gene most commonly mutated in haemochromatosis, the clinical definition was affected by ascertainment bias. Even after the identification of the $H F E$ gene, estimates of the frequency with which diabetes and other morbidities accompany haemochromatosis vary widely [25]. In the current study, the prevalence of abnormal glucose homeostasis in adult subjects with haemochromatosis referred to our research clinic was $53 \%$. This was significantly higher than in the control group of siblings who were wild-types or heterozygotes for the common haemochromatosis mutations $\mathrm{C} 282 \mathrm{Y}$ or $\mathrm{H} 63 \mathrm{D}$ in the HFE gene. These data suggest that screening for diabetes and abnormal glucose tolerance in individuals with haemochromatosis is warranted and may be more sensitive if performed using glucose tolerance testing rather than fasting glucose analysis alone.

The prevalence of diabetes in the individuals with haemochromatosis was $23 \%(7 / 30)$. Because this number was unexpectedly high, we determined the prevalence of diabetes from medical records of 272 subjects previously referred to the Haemochromatosis Research Clinic, and the frequency of diabetes was similar: $26 \%$ of 137 subjects had fasting glucose values $>7 \mathrm{mmol} / 1$, and the self-reported prevalence of diabetes in 135 subjects for whom no fasting glucose values were available was $20 \%$. These studies were limited to subjects in the age range 40-79 years. The estimates of diabetes prevalence are probably underestimated in the self-reporting study, both because of the well-known underdiagnosis of the disease and because most of the patients were seen at a time when the fasting glucose threshold for the definition of diabetes was $7.8 \mathrm{mmol} / \mathrm{l}(140 \mathrm{mg} / \mathrm{dl})$. The population with haemochromatosis is overwhelmingly white, and the frequency of diabetes expected in a population of this age and ethnicity is $2-9 \%$ [21]. Thus, there are strong indications that the prevalence of diabetes in haemochromatosis is significantly increased compared with control populations. Most of these data are still subject to some degree of ascertainment bias, and we are continuing to assess siblings of probands who have not themselves sought medical care in order to get better estimates of true diabetes prevalence.

The current data are relevant to a controversial issue in the literature, namely the frequency of haemochromatosis subjects in populations with type 2 diabetes. There have been reports of significant increases in the frequency of HFE mutations in diabetes clinic populations [26, 27], although other studies have failed to see such increases [28-32]. If the frequency of haemochromatosis subjects in white populations is $0.5 \%[1,2]$ and $20 \%$ of those adults have diabetes, then the frequency of adult diabetic individuals with haemochromatosis in the population will be approximately $0.1 \%$. If the frequency of diabetes in white populations of similar age were $5-10 \%$, then we might expect $0.1 / 5$ to $0.1 / 10$, or 1 to $2 \%$ of white individuals in adult diabetes clinics to have haemochromatosis. This would represent an approximately four-fold enrichment of haemochromatosis homozygotes in typical diabetes clinics, and the previous studies in the literature may not have had sufficient power to detect such small increases. This conclusion should also be tempered with the fact that the current study of referrals to an haemochromatosis clinic may not be without selection bias, so the true prevalence of disease in the total population may differ from that ascertained in this study. Most such biases would probably be in the direction of over-representation of individuals with complications, so even the relatively small increase predicted above might be overestimated, suggesting that general screening of typical diabetes clinic populations for HFE mutations might not be warranted. In subgroups of diabetics, namely white males, those with late-onset insulin-deficient diabetes, or individuals with abnormal liver function, arthropathy or hypogonadism, HFE screening may be effective. Consistent with this, one Italian study reported that haemochromatosis was 43 times more likely in subjects who had a combination of liver disease and diabetes [33], and a Danish study found a significant increase in C282Y homozygosity in individuals with late-onset type 1 diabetes [34].

In the current study cohort, all individuals with diabetes were male (NS), and in the retrospective review men were found to be more prone to haemochromatosis-associated diabetes than women. This is probably due to shorter and/ or less severe exposures to iron overload in women, perhaps as a consequence of menstrual blood loss or other protective effects of oestrogen on diabetes risk.

A substantial proportion of the subjects with significant iron overload had no detectable abnormality of glucose homeostasis. This is consistent with the large degree of phenotypic variation in terms of other morbidities in subjects with haemochromatosis that has been attributed at least in part to other genetic modifiers $[22,35]$. Our studies of mouse models of the disease demonstrate that iron 
overload may actually be protective of diet-induced obesity (unpublished results), and the same mechanisms may be operative in humans.

In our control group we included heterozygote siblings of individuals with haemochromatosis because earlier studies have shown that heterozygotes for HFE mutations have only slightly higher iron indices than wild-types and are not affected by the morbidities attendant with homozygosity [16, 36], and do not exhibit abnormalities in insulin resistance or secretion [37]. The study of mouse models of haemochromatosis also suggests that iron overload and not the HFE mutations per se are responsible for the glucose homeostasis phenotype [15], and the heterozygous controls in this study did not have elevated serum ferritin concentrations. Further support for the primary role of iron in the pathogenesis of haemochromatosis-associated diabetes is found in reports that even in the absence of $H F E$ mutations individuals with diabetes have higher than average iron indices [38-40].

Our studies of mouse models of haemochromatosis revealed that beta cell mass is decreased secondary to apoptosis [15]. This is likely to be the case in humans as well, since at the stage of IGT the AIRg was significantly decreased. In the mouse models, the decreased insulin secretory capacity is compensated for by increased $\mathrm{Si}$, such that NGT or supranormal glucose tolerance is maintained [15]. Similarly in the humans with haemochromatosis, there was no evidence for insulin resistance in these individuals, and conversely, there was a trend toward an increase in $\mathrm{Si}$ in all of the data (FSIVGTT, QUICKI and clamp), although the Si did not increase significantly. The current evidence for a beta cell defect in haemochromatosis and for a pathogenic role of iron in the beta cell is supported by some prior studies. A relatively small study of subjects with haemochromatosis found that regardless of whether the subjects did $(n=6)$ or did not $(n=7)$ have diabetes, there was a significant decrease in the acute insulin response to glucose (AIRg) during an IVGTT [10]. Phlebotomy increased the AIRg by 35\% [10]. Further support for a toxic effect of iron on the beta cell comes from studies of patients with thalassaemia major [41] and rats subjected to experimental iron overload [42]. Why iron overload might lead to impaired beta cell function is not clear. High levels of the divalent metal transporter are seen in beta cells, presumably because of the need for zinc in packaging insulin in secretory granules [43]. Non-proteinbound iron can also enter the cell via this transporter, and in haemochromatosis free-iron levels will rise with saturation of transferrin. Iron flux through this pathway and/or particular susceptibility of beta cells to oxidative damage might explain the unusually high levels of ferritin in normal beta cells [44].

The different tests of Si used in this study reflect glucose homeostasis under very different degrees of insulinaemia and carbohydrate loading, and none suggest insulin resistance in the pre-diabetic population. The association of insulin resistance with iron overload is largely based on studies of subjects with beta thalassaemia, transfusion iron overload, coexistent liver disease or idiopathic hyperferritinaemia $[11,12,40,45,46]$. The different distributions of iron in these conditions compared with haemochromatosis (reticuloendothelial vs hepatocellular) $[1,47]$ may explain the differing phenotypes. The studies that have implicated insulin resistance specifically in hereditary haemochromatosis have studied subjects with established diabetes $[10,48]$ and hyperglycaemia is by itself a major determinant of $\mathrm{Si}$ [13]. Although not supporting a primary phenotype of insulin resistance in haemochromatosis, the current results do suggest that the transition from IGT to diabetes may involve insulin resistance in some cases. All the current subjects who became diabetic were overweight, and it is possible that the failing beta cells are unable to counteract the obesity-associated insulin resistance with increased insulin secretion. Another subject, however, had very high $\mathrm{Si}$ accompanied by extremely low insulin secretion, suggesting the possibility that a primary defect of insulin secretion may progress to diabetes even in the absence of insulin resistance. A final relevant observation is that most of the subjects who developed diabetes in the chart review study also had significant liver damage (Table 3). This may be a simple association based on the fact that exposure to high levels of iron for long periods may damage the liver and beta cell in parallel. Cirrhosis, hepatitis and hepatic iron overload are themselves, however, associated with insulin resistance $[12,49]$. Hramiak et al. reported that in the absence of cirrhosis and diabetes, $\mathrm{Si}$ was normal in subjects with haemochromatosis [10]. Finally, because 'garden variety' type 2 diabetes has an expected prevalence of $5-10 \%$ in this population, a significant proportion of the subjects with diabetes and haemochromatosis may have type 2 diabetes independent of their iron status.

In summary, we have demonstrated that abnormal glucose tolerance and diabetes are seen at significant frequencies in individuals with haemochromatosis. This justifies glucose tolerance testing of individuals with haemochromatosis as well as prophylactic phlebotomy in unaffected individuals with haemochromatosis. This may be especially important for the prevention of diabetesrelated morbidities that can occur very early or even at prediabetic stages of the disease. The loss of insulin secretory capacity is the primary event leading to haemochromatosisrelated diabetes, although secondary insulin resistance related to obesity or hepatic damage may contribute to the ultimate expression of diabetes. The reversibility of the insulin secretion abnormalities is under study, as are further details of the effects of iron on glucose homeostasis and of the possible modifiers that affect disease expression.

Acknowledgements This work was supported by the Research Service of the Veterans Administration, the National Institutes of Health (RO1 DK059512), the Huntsman General Clinical Research Center (MO1 RR000064), and the Ben B. and Iris M. Margolis Foundation. 


\section{References}

1. Edwards C (1999) Hemochromatosis. In: Lee GR, Foerster J, Lukens J, Paraskevas F, Greer JP, Rodgers GM (eds) Wintrobe's Clinical Hematology. Williams \& Wilkins, Baltimore, Massachusetts, pp 1056-1070

2. Bothwell THCR, Motulsky AG (1995) Hemochromatosis. In: Scriver CR, Beaudet A, Sly WS, Valle D (eds) The metabolic and molecular bases of inherited disease. McGraw-Hill, New York, pp 2237-2269

3. Feder JN, Gnirke A, Thomas W et al (1996) A novel MHC class I-like gene is mutated in patients with hereditary haemochromatosis. Nat Genet 13:399-408

4. Feder JN, Tsuchihashi Z, Irrinki A et al (1997) The hemochromatosis founder mutation in HLA-H disrupts beta2-microglobulin interaction and cell surface expression. J Biol Chem 272:14025-14028

5. Nemeth E, Roetto A, Garozzo G, Ganz T, Camaschella C (2005) Hepcidin is decreased in TFR2 hemochromatosis. Blood 105(4):1803-1806

6. Nemeth E, Tuttle MS, Powelson J et al (2004) Hepcidin regulates cellular iron efflux by binding to ferroportin and inducing its internalization. Science 306:2090-2093

7. Edwards CQ, Dadone MM, Skolnick MH, Kushner JP (1982) Hereditary haemochromatosis. Clin Haematol 11:411-435

8. Buysschaert M, Paris I, Selvais P, Hermans MP (1997) Clinical aspects of diabetes secondary to idiopathic haemochromatosis in French-speaking Belgium. Diabetes Metab 23:308-313

9. Moirand R, Adams PC, Bicheler V, Brissot P, Deugnier Y (1997) Clinical features of genetic hemochromatosis in women compared with men. Ann Intern Med 127:105-110

10. Hramiak IM, Finegood DT, Adams PC (1997) Factors affecting glucose tolerance in hereditary hemochromatosis. Clin Invest Med 20:110-118

11. Merkel PA, Simonson DC, Amiel SA et al (1988) Insulin resistance and hyperinsulinemia in patients with thalassemia major treated by hypertransfusion. N Engl J Med 318:809-814

12. Mendler MH, Turlin B, Moirand R et al (1999) Insulin resistance-associated hepatic iron overload. Gastroenterology 117:1155-1163

13. Rossetti L, Giaccari A, DeFronzo RA (1990) Glucose toxicity. Diabetes Care 13:610-630

14. Bugianesi E, Manzini P, D'Antico S et al (2004) Relative contribution of iron burden, HFE mutations, and insulin resistance to fibrosis in nonalcoholic fatty liver. Hepatology 39:179-187

15. Cooksey RC, Jouihan HA, Ajioka RS et al (2004) Oxidative stress, beta-cell apoptosis, and decreased insulin secretory capacity in mouse models of hemochromatosis. Endocrinology 145:5305-5312

16. Adams PC, Reboussin DM, Barton JC et al (2005) Hemochromatosis and iron-overload screening in a racially diverse population. N Engl J Med 352:1769-1778

17. Guttridge MG, Thompson J, Worwood M, Darke C (1998) Rapid detection of genetic mutations associated with haemochromatosis. Vox Sang 75:253-256

18. Alberti KG, Zimmet PZ (1998) Definition, diagnosis and classification of diabetes mellitus and its complications. Part 1: diagnosis and classification of diabetes mellitus provisional report of a WHO consultation. Diabet Med 15:539-553

19. Saad MF, Steil GM, Riad-Gabriel M et al 1997 Method of insulin administration has no effect on insulin sensitivity estimates from the insulin-modified minimal model protocol. Diabetes 46:2044-2048

20. Boston RC, Stefanovski D, Moate PJ, Sumner AE, Watanabe RM, Bergman RN (2003) MINMOD Millennium: a computer program to calculate glucose effectiveness and insulin sensitivity from the frequently sampled intravenous glucose tolerance test. Diabetes Technol Ther 5:1003-1015
21. Kenny S, Aubert RE, Geiss LS (1995) Prevalence and incidence of non-insulin-dependent diabetes. In: Health NIo, Diseases NIoDaDaK (eds) National Diabetes Data Group. National Institutes of Health, National Institute of Diabetes and Digestive and Kidney Diseases, Bethesda, Maryland, pp 47-68

22. Bulaj ZJ, Ajioka RS, Phillips JD et al (2000) Disease-related conditions in relatives of patients with hemochromatosis. N Engl J Med 343:1529-1535

23. Kahn SE, Prigeon RL, McCulloch DK et al (1993) Quantification of the relationship between insulin sensitivity and beta-cell function in human subjects. Evidence for a hyperbolic function. Diabetes 42:1663-1672

24. Chen H, Sullivan G, Quon MJ (2005) Assessing the predictive accuracy of QUICKI as a surrogate index for insulin sensitivity using a calibration model. Diabetes 54:1914-1925

25. Ajioka RS, Kushner JP (2002) Hereditary hemochromatosis. Semin Hematol 39:235-241

26. Kwan T, Leber B, Ahuja S, Carter R, Gerstein HC (1998) Patients with type 2 diabetes have a high frequency of the $\mathrm{C} 282 \mathrm{Y}$ mutation of the hemochromatosis gene. Clin Invest Med 21:251-257

27. Moczulski DK, Grzeszczak W, Gawlik B (2001) Role of hemochromatosis C282Y and H63D mutations in HFE gene in development of type 2 diabetes and diabetic nephropathy. Diabetes Care 24:1187-1191

28. Braun J, Donner H, Plock K, Rau H, Usadel KH, Badenhoop K (1998) Hereditary haemochromatosis mutations (HFE) in patients with type II diabetes mellitus. Diabetologia 41:983-984

29. Dubois-Laforgue D, Caillat-Zucman S, Djilali-Saiah I et al (1998) Mutations in HFE, the hemochromatosis candidate gene, in patients with NIDDM. Diabetes Care 21:1371-1372

30. Frayling T, Ellard S, Grove J, Walker M, Hattersley AT (1998) C282Y mutation in HFE (haemochromatosis) gene and type 2 diabetes. Lancet 351:1933-1934

31. Halsall DJ, McFarlane I, Luan J, Cox TM, Wareham NJ (2003) Typical type 2 diabetes mellitus and HFE gene mutations: a population-based case-control study. Hum Mol Genet 12:1361-1365

32. Sampson MJ, Williams T, Heyburn PJ et al (2000) Prevalence of HFE (hemochromatosis gene) mutations in unselected male patients with type 2 diabetes. J Lab Clin Med 135:170-173

33. Conte D, Manachino D, Colli A et al (1998) Prevalence of genetic hemochromatosis in a cohort of Italian patients with diabetes mellitus. Ann Intern Med 128:370-373

34. Ellervik C, Mandrup-Poulsen T, Nordestgaard BG et al (2001) Prevalence of hereditary haemochromatosis in late-onset type 1 diabetes mellitus: a retrospective study. Lancet 358:1405-1409

35. Valenti L, Conte D, Piperno A et al (2004) The mitochondrial superoxide dismutase A16V polymorphism in the cardiomyopathy associated with hereditary haemochromatosis. J Med Genet 41:946-950

36. Bulaj ZJ, Griffen LM, Jorde LB, Edwards CQ, Kushner JP (1996) Clinical and biochemical abnormalities in people heterozygous for hemochromatosis. N Engl J Med 335:1799-1805

37. Van Lerberghe S, Hermans MP, Dahan K, Buysschaert M (2002) Clinical expression and insulin sensitivity in type 2 diabetic patients with heterozygous mutations for haemochromatosis. Diabetes Metab 28:33-38

38. Jiang R, Manson JE, Meigs JB, Ma J, Rifai N, Hu FB (2004) Body iron stores in relation to risk of type 2 diabetes in apparently healthy women. JAMA 291:711-717

39. Wilson JG, Lindquist JH, Grambow SC, Crook ED, Maher JF (2003) Potential role of increased iron stores in diabetes. Am J Med Sci 325:332-339

40. Tuomainen TP, Nyyssonen K, Salonen R et al (1997) Body iron stores are associated with serum insulin and blood glucose concentrations. Population study in 1,013 eastern Finnish men. Diabetes Care 20:426-428 
41. Mangiagli A, Italia S, Campisi S (1998) Glucose tolerance and beta-cell secretion in patients with thalassemia major. J Pediatr Endocrinol Metab 11:985-986

42. Pelot D, Zhou XJ, Carpenter P, Vaziri ND (1998) Effects of experimental hemosiderosis on pancreatic tissue iron content and structure. Dig Dis Sci 43:2411-2414

43. Andrews NC (1999) The iron transporter DMT1. Int J Biochem Cell Biol 31:991-994

44. MacDonald MJ, Cook JD, Epstein ML, Flowers CH (1994) Large amount of (apo)ferritin in the pancreatic insulin cell and its stimulation by glucose. FASEB J 8:777-781

45. Cario H, Holl RW, Debatin KM, Kohne E (2003) Insulin sensitivity and beta-cell secretion in thalassemia major with secondary haemochromatosis: assessment by oral glucose tolerance test. Eur J Pediatr 162:139-146
46. Fernandez-Real JM, Lopez-Bermejo A, Ricart W (2002) Cross-talk between iron metabolism and diabetes. Diabetes 51:2348-2354

47. Turlin B, Mendler MH, Moirand R, Guyader D, Guillygomarc'h A, Deugnier Y (2001) Histologic features of the liver in insulin resistance-associated iron overload. A study of 139 patients. Am J Clin Pathol 116:263-270

48. Dubois-Laforgue D, Caillat-Zucman S, Boitard C, Timsit J (2000) Clinical characteristics of type 2 diabetes in patients with mutations of HFE. Diabetes Metab 26:65-68

49. Caronia S, Taylor K, Pagliaro L et al (1999) Further evidence for an association between non-insulin-dependent diabetes mellitus and chronic hepatitis $\mathrm{C}$ virus infection. Hepatology 30:1059-1063 